\title{
LA PRAGMÁTICA DEL DISCURSO POÉTICO CON ESPECIAL ATENCIÓN A LA TEMPORALIDAD LINGÜÍSTICA
}

«La conquista de la poesía es como la del amor, que nunca sabremos si su secreto es nuestro, y contamos para siempre con la belleza y la fuerza de esa duda.»

Juan Ramón Jiménez, Estética y Ética estética

\section{Introducción. De la lingüística textual a la pragmática ${ }^{1}$}

El hecho de que el significado global de un texto resulta superior a la simple suma de las significaciones de las oraciones que lo componen, originó el conocido cambio de paradigma en el desarrollo de la investigación lingüística: el paso de la oración al texto. Como el texto llegó a ser la clave para el estudio lingüístico fue imprescindible la reconsideración global de la naturaleza de la lengua lo que suponía ciertas ampliaciones del concepto de la lingüística tradicional. Surgió la disciplina llamada Lingüística textual o Sintaxis textual ${ }^{2}$ cuyo objeto sería el estudio de la lengua a partir de su manifestación en textos. Por una parte se concibe el texto como la unidad global del acto de comunicación y por otra se lo considera como el encadenamiento de estructuras sintácticas particulares. Los límites entre sintaxis, semántica y pragmática se hacen borrosos puesto que el texto ya no se concibe como una estructura cerrada, sino como proceso de significación, abierto a interpretaciones subjetivas diferentes.

La necesidad de redefinir los conceptos de la lengua y del texto dio lugar a varias direcciones en la lingüística textual pero todas coinciden, primero, en que el texto posee determinado valor semántico, segundo, en que el texto es un resultado de un acto comunicativo que ocurre en una situación concreta y tercero, en que lo origina una estructura profunda, llamada macroestructura, cuya antítesis es la estructura superficial o microestructura. Estos tres postulados junto con la distinción entre la oración (entidad abstracta) y el enunciado (cada una de las realizaciones particulares) ${ }^{3}$ paralela a la que se establece entre el texto y el discurso han motivado la pregunta: ¿qué hace la gente cuando usa el lenguaje? Y la pragmática empieza precisamente como un intento de encontrar el sentido a la conducta lingüística.

Es bien sabido que la pragmática forma parte de una tríada ${ }^{4}$, cuyas otras dos componentes son la sintaxis y la semántica. El conjunto de las tres constituye una teoría lingüística o, más en general, una teoría semiótica del lenguaje. Según nuestra opinión esta división en sintaxis, semántica y pragmática es la que, cuando aplicada a la literatura, puede dar

\footnotetext{
1 No se pretende hacer aquí un panorama exhausto del desarrollo de estas dos corrientes sino sólo exponer los puntos principales que nos serán útiles para el objetivo de este artículo.

2 Entre otras denominaciones cabe recordar la de gramática textual en sus principios, lingüística del texto; lingüística del discurso; o la lingüística del habla como la llama E. Coseriu.

3 Véase O. Ducrot (1984).

4 Siguiendo a C. Morris (1985: 31) que expone tres dimensiones de la semiótica: dimensión semántica (que estudia las relaciones de los signos con los objetos a los que son aplicables), dimensión pragmática (que estudia la relación de los signos con los intérpretes) y dimensión sintáctica (que estudia la relación de los signos entre sí).
} 
cuenta de la totalidad del proceso comunicativo y permite, por tanto, abordar el estudio de la obra literaria en sus tres aspectos: formal, significante y de uso.

Pero el papel que desempeña la investigación pragmática en el campo lingüístico no ha sido del todo claro ya que se ocupa sobre todo de los elementos extralinguísticos. A consecuencia de esto han surgido varias concepciones y definiciones tanto del término mismo como del campo de la investigación pragmática ${ }^{5}$ y se han visto implicadas en los trabajos pragmáticos diversas disciplinas: la Filosofía, la Linguiística, la Psicología, la Sociología y la Antropología. Por otra parte, en ese deseo de superar el estudio de los sistemas se enmarcan también las llamadas corrientes de Análisis del discurso (o de Análisis de la conversación).

En estudios pragmático-lingüísticos se han tomado diversas direcciones. Las más usuales destacan la importancia del estudio de la lengua en su contexto; otras enfatizan el análisis de la lengua como acción basándose en la suposición de que hablar sea actuar de un cierto modo ${ }^{6}$. La pragmática inferencial ${ }^{7}$, por otra parte, consiste en la descripción de las estrategias que permiten recobrar informaciones intencionalmente comunicadas, pero de manera implícita.

El hecho de que es difícil establecer una separación tajante entre la lingüística y la pragmática se manifiesta también en varios intentos de encontrar la denomincación adecuada de la «nueva perspectiva» en la lingüística: la pragmática lingüística de G. Reyes (1990), la pragmática del discurso de T. Van Dijk (1998) y la lingüística pragmática de C. Fuentes Rodríguez (2000) ${ }^{8}$ son unos de los ejemplos más rentables. J. M. Adam (1990), a su vez, propone una pragmática textual (la iguala a lingüística textual) integrando así el análisis estructural con el pragmático y el textual sin olvidar los estudios argumentativos, necesarios para explicar el sentido de los enunciados. Sostiene que todas las oraciones hay que analizarlas en relación con el todo, viendo las conexiones, la progresión, la referencia, y el acto de enunciación o modalización.

La postura de G. Reyes de que la pragmática es, por una parte, el estudio de cómo significa el lenguaje cuando es usado para la comunicación, y, por otra, el estudio de las propiedades lingüísticas que la hacen posible, desemboca en la importante relevancia de la autorreferencialidad de toda comunicación. Esta metapragmática hace ver, según G. Reyes (2002), cómo pensamos la pragmática los hablantes al hablar y cómo la reflexión sobre el uso del lenguaje regula y contribuye a hacer posible el uso del lenguaje. Y, en efecto, no hay pragmática - uso de la lengua - sin metapragmática - alguna conciencia del uso; lo importante es entonces ver la pragmática y metapragmática como dos conjuntos de prácticas simultáneas en nuestra actividad linguística cotidiana y estudiar más detenidamente su estrecha relación.

Actualmente los estudios pragmáticos se orientan fundamentalmente en tres direcciones atendiendo a los tres aspectos del texto: el productivo, el comunicativo y el receptivo. Para

5 Su papel sigue siendo debatible; mostrémoslo con la ilustrativa comparación de Van Dijk (1998: 270): «la pragmática es el cesto de los papeles del gramático».

6 La influencia clara de los modelos filosóficos de J. L. Austin y J. R. Searle.

7 El investigador más representativo de esta dirección es H. P. Grice que identifica cuatro máximas de conversación (de calidad, de cantidad, de relevancia, de modo) que, según él, son los principios subyacentes sobre los cuales se basa el uso cooperativo eficiente de la lengua.

8 Fuentes Rodríguez centra su atención en cómo se organiza en estructuras dicursivas la influencia de lo extralingüístico sobre lo lingüístico, lo que es, según nuestra opinión, en realidad el fin de toda pragmática: formalizar dichas interconexiones. 
el objetivo del presente artículo el más relevante será el segundo, es decir el aspecto que tiene como base teórica los actos de habla y se ocupa de la obra literaria como proceso comunicativo. Y en lo que se refiere a la relación entre la pragmática y la lingüística, podemos concluir que los objetivos de la pragmática son plenamente lingüísticos y gramaticales, y no objeto de una nueva disciplina. Coincidimos con C. Fuentes Rodríguez (2000) que sostiene que pragmática es sólo un adjetivo, ya que la lingüística actual debe ser pragmática, debe atender al estudio de la lengua en su totalidad y en su contexto propio.

\section{Principios de textualidad (cohesión y coherencia)}

En este artículo entendemos la lengua como el sistema necesariamente interactivo, de ahí que el texto sea, en su esencia, un fenómeno comunicativo, un intercambio social que produce sentido. Por lo que atañe a los principios constitutivos del texto nos centraremos en cohesión y coherencia que son quizás los aspectos más fundamentales del texto y donde más explícitamente se manifiestan las relaciones temporales aunque no presenten una caracterización muy homogénea entre los investigadores. Todos comparten, sin embargo, la convicción de que, primero, la cohesión es la manifestación superficial de una propiedad más profunda que es la coherencia y de que la coherencia es una propiedad fundamental de los textos, hasta tal punto que podemos definir texto como objeto lingüístico dotado de coherencia. Para el presente estudio han sido tomado como puntos de partida los siguientes tres modelos: el de R. de Beaugrande y O. Dressler (1997), donde la cohesión viene a equivaler a una «sintaxis textual» mientras que la coherencia se refiere al contenido (más que al significado); el modelo de E. Bernárdez (1995) que, por otra parte, distingue entre cohesión superficial (sintáctica); cohesión semántico-temática (que es la coherencia de R. de Beaugrande y O. Dressler) y coherencia que es un fenómeno pragmático que, por tanto, interviene ya antes de la estructuración propiamente lingüística del texto y depende directamente de la intención comunicativa del hablante. Y, por último, el modelo de la coherencia pragmática o global de T. Van Dijk (1997) que es la que la asigna el lector en su proceso de interpretación.

No hay que olvidar, sin embargo, la importancia de las condiciones previas $^{9}$ y los mecanismos textuales centrados en el contexto. Las primeras se refieren a los participantes del acto comunicativo: la intencionalidad del productor del texto que, a fin de conseguir ciertos objetivos, intenta un texto cohesivo y coherente, y la aceptabilidad, es decir la actitud del receptor del texto que espera un texto cohesivo y coherente que para él es útil y relevante. Los mecanismos centrados en el contexto son, a su vez, la situacionalidad, la informatividad y la intertextualidad, donde la primera abarca los factores que hacen a un texto relevante en una situación comunicativa actual o reconstruible; la segunda representa la dimensión de las expectativas o grado de novedad del mismo; y la tercera incluye los factores que la utilización de un texto hace dependientes del conocimiento de uno o varios textos anteriores.

\section{Del texto al discurso. Pragmática del poema lírico}

Para empezar a hablar sobre la pragmática de un poema insistimos, primero, en la presuposición de que el texto poético es una comunicación lingüística. Pero al mismo

\footnotetext{
${ }^{9}$ Siguiendo el modelo de R. de Beaugrande y U. Dressler (1997).
} 
tiempo queremos enfatizar la importancia del carácter peculiar de tal comunicación que todo análisis textual tiene que tomar como punto de partida. Así, por ejemplo, la intención comunicativa del autor al emitir su mensaje no es urgente ni inmediata (como lo es en la conversación) y carece en principio de la finalidad práctica, informativa o interpersonal. A su vez el receptor/lector parece que tiene un papel de participante pasivo mas es todo lo contrario. El hecho es que todo en el texto poético no es ni verdadero ni falso sino que es fingido; los actos de habla son ficticios, o hasta parasitarios y devaluados puesto que no tienen la fuerza ilocutiva que les correspondería como enunciados verdaderos. Sin embargo, dentro del poema se crea una comunicación virtual que funciona al modo de la comunicación cotidiana. Coincidimos con B. Herrenstein Smith (1993) que dice que un poema no es la representación de cosas, sino la representación de un discurso sobre cosas, es decir de un discurso ficticio a diferencia del discurso natural ${ }^{10}$. Mirándolo así el poema es la representación de una comunicación en la que el lector debe suponer todas las condiciones que hacen que dicha comunicación funcione. Ahora bien, el acto comunicativo del poema se desprende en tres niveles: el nivel establecido entre los personajes explícitamente presentes en el texto (es el nivel que B. Herrenstein Smith llama la comunicación interna); el nivel entre autor y lector reales (o la comunicación externa), y el nivel entre el autor y lector implícitos (una comunicación que media entre las dos). Creemos que justamente las complicadas relaciones entre los tres niveles de comunicación en un discurso poético originan la complejidad de la poesía lírica que es la que nos interesa en el presente artículo.

La cuestión pragmática de la relación entre los «hablantes» en la comunicación lírica adquiere notas especiales. Así, pues, un rasgo destacado de la lírica será su escasa circunstanciación que hace que el lector reconstruya imaginativamente todos los elementos de la enunciación. El papel del lector es entonces todo lo opuesto a lo pasivo. En un poema lírico la cuestión del hablante poético, del yo inmanente, es quizá la cuestión central en la pragmática de este género. La situación comunicativa de la lírica es así fundamentalmente expresiva y especial interés tiene analizar la relación yo-tú. Nosotros nos centraremos en la pragmática intratextual, lo que quiere decir que nos interesará la comunicación que se produce dentro del poema entre un hablante ficticio y un oyente igualmente ficticio. Creemos que así se revelarán también las peculiares relaciones lingüísticas donde más nos interesará la temporalidad verbal.

En cuanto al lenguaje poético, primero hay que señalar que un poema normalmente aparece aislado de contexto y de situación. Todo lo que el autor dice lo dice exclusivamente mediante procedimientos lingüísticos de modo que todos los recursos que utilice tienen que ser significativos, comunicar algo. Eso demuestra, según Alarcos Llorach (1973), que un poema es el ejemplo más puro de comunicación lingüística. Su valor estético se halla así en la habilidad del autor para explotar al máximo los recursos de una lengua y conseguir que todo, tanto secuencia de expresiones como secuencia de contenidos sea pertinente. De ahí se desprende que el lenguaje poético no es más que la lengua drásticamente limitada a sus propias y exclusivas posibilidades de comunicación. J. Guillén (1992), por otra parte, rechaza categóricamente que la poesía requiera especial lenguaje poético. Y estamos de acuerdo con él cuando afirma que ninguna palabra está de antemano

${ }^{10}$ B. Herrenstein Smith (1993) sostiene que los poemas no son enunciados naturales, ni actos o sucesos verbales históricamente únicos; no son sucesos en absoluto ya que no se puede decir que hayan «ocurrido» alguna vez en el sentido normal de su término. 
excluida y que cualquier expresión puede configurar la frase poética. Todo depende, pues, del contexto; sólo es poético el uso, no hay más que el lenguaje de poema, o sea de discurso poético, que lo constituyen las palabras situadas en un conjunto.

Actualmente se habla de texto o de discurso indistintamente para referirse a la dimensión en que operan unidades comunicativas antes que gramaticales. Estos términos se utilizan como sinónimos ya que el enfoque pragmático actual ha entrelazado la Lingüística del texto con el Análisis del discurso, dos perspectivas que antes se diferenciaban según la unidad texto se estudiara como producto o como proceso interactivo y dinámico. Pero, sin embargo, nosotros preferimos mantener la diferencia y emplear el término discurso $^{11}$, lo que en nuestro análisis es el discurso poético, debido a su mayor amplitud que se origina ya en su contenido léxico-semántico: discurrir del discurso frente al tejer, textura del texto. Así es que llamamos el discurso poético un intercambio tanto de los significados como de los actos de habla y es ahí, en el acto del lenguaje llamado enunciación donde se genera la dimensión coactiva.

\section{Temporalidad lingüística}

El enfoque pragmático engloba el signo literario con la perspectiva dinámica teniendo en cuenta las variantes de uso, de manera que supera tanto los métodos extrínsecos como los métodos inmanentistas de investigación del discurso literario. Ahora bien, creemos que es necesario partir de este concepto coactivo también y sobre todo en el momento de analizar las relaciones temporales de una red textual. Sin embargo, la aproximación lingüística al concepto de tiempo se encuentra ante un problema mucho más hetereogéneo de lo que aparece a primera vista. Una buena parte de los problemas que presenta el estudio de los tiempos verbales se debe, por una parte, a la falta de una distinción clara entre la noción que los seres humanos tenemos del tiempo y las características que la categoría lingüística de tiempo presenta en una lengua, pero por otra, a la obsesión de eliminar cualquier relación lógica entre dichos elementos. La postura de la incompatibilidad de Tiempo como molde para formar conceptos lingüísticos ha sido señalada ya por W. E. Bull (1960) como también por H. Weinrich (1974) en el campo de las lenguas románicas. Estos autores afirman que ninguna forma temporal localiza un suceso en el Tiempo de ahí que los tiempos verbales señalen no el Tiempo de la acción, sino el orden y el aspecto de la misma en el Tiempo. Entre ellos H. Weinrich toma la postura más radical en el intento de negar y eliminar toda relación entre el tiempo real y el tiempo verbal.

E. Benveniste (1966) partió de la inadecuación de los planteamientos tradicionales de la temporalidad verbal y postuló su sistema teórico en el establecimiento de dos grupos de formas verbales (tiempos de la historia y tiempos del discurso); lo que en Weinrich es la distinción entre los tiempos del mundo narrado y los tiempos del mundo comentado. La oposición canta/cantaba desde esta perspectiva no nos dice nada sobre el Tiempo del cantar. Los tiempos presente e imperfecto nos están informando más bien sobre el modo como tenemos que escuchar. El presente, como tiempo principal del mundo comentado, designa actitud comunicativa diferente a la que se expresa con el imperfecto. Éste último posibilita al hablante que adopte el papel del narrador desplazando la situación comunicativa a otro plano, lo que no significa el desplazamiento al pasado sino a otro plano de conciencia.

\footnotetext{
${ }^{11}$ Siguiendo a J. M. Adam (1990: 23): «DISCOURS = Texte + Conditions de production; TEXTE = Discours - Conditions de production.», o bien a T. Van Dijk (1980): «texto: texto sin contexto; discurso: texto con contexto».
} 
Una línea un poco más moderada en cuanto a la ruptura entre el Tiempo y los tiempos ha sido trazada de por B. Pottier y V. Lamíquiz, donde el punto de partida se halla en diferentes niveles o planos de actualidad (tiempos del plano actual frente a tiempos del plano inactual). E. Alarcos Llorach, a su vez, establece la diferenciación entre dos perspectivas (de presente o participación y de pasado o alejamiento). Son estas dos últimas las que nos servirán de base para nuestro análisis.

Creemos que la relación entre el tiempo como concepto filosófico (o psicológico, etc.) y los tiempos linguísticos todavía sigue siendo un importante objetivo de las investigaciones dado que la naturaleza de esta relacién (o, mejor dicho, de las relaciones) es mucho más compleja y no la podemos reducir a una simple dicotomía de existencia/no existencia. Pero uno de los puntos de partida imprescindibles para comprender correctamente el funcionamiento de los mecanismos verbales de la temporalidad es la distinción entre el tiempo físico, su correlato humano el tiempo psíquico, el tiempo cronológico (su versión objetiva y subjetiva) y el tiempo lingüístico ${ }^{12}$. Es éste último el que nos interesa: se fundamenta en el establecimiento de un origen que es móvil y normalmente (pero no siempre) coincide con el momento de enunciación convirtiendo así a cada acto lingüístico en su propio centro de referencia temporal, con respecto al cual los acontecimientos pueden ser anteriores, simultáneos o posteriores. Preferimos emplear el término de la temporalidad verbal (G. Rojo: 1974) al tiempo verbal para referirnos únicamente a las relaciones temporales propias de los elementos lingüísticos. Al mismo tiempo la noción de temporalidad lingüística nos parece más adecuada para la descripción de las formas verbales de indicativo.

Para el análisis lingüístico que seguirá a continuación tomaremos como base el modelo de G. Rojo (1974: 78):

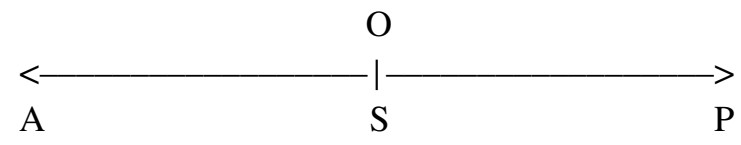

Con relación al origen $(\mathrm{O})$, un hecho no puede ser más que anterior $(\mathrm{A})$, simultáneo (S) o posterior $(\mathrm{P})$. Considerando estas diferentes orientaciones como vectores, podemos establecer tres fórmulas que simbolizan estas tres relaciones (donde $\mathbf{A}$ es acontecimiento, $\mathbf{O}$ origen, $-\mathbf{V}$ vector que simboliza anterioridad, $\mathbf{o} \mathbf{V}$ vector que simboliza simultaneidad $\mathrm{y}+\mathbf{V}$ vector que simboliza posterioridad):

$$
\mathrm{A}(\mathrm{O}-\mathrm{V}) ; \quad \mathrm{A}(\mathrm{O} \circ \mathrm{V}) ; \quad \mathrm{A}(\mathrm{O}+\mathrm{V})
$$

Cabe señalar que un acontecimiento puede estar situado no sólo con relación al origen sino también con respecto a otros acontecimientos que, a su vez, mantienen una determinada relación temporal al origen. Entre las formas verbales personales de indicativo las referidas directamente al origen son canté: $\mathrm{O}-\mathrm{V}$; canto: $\mathrm{O}$ o V; cantaré: $\mathrm{O}+\mathrm{V}$. Las formas situadas con respecto a punto anterior al origen son entonces: había cantado: $(\mathrm{O}$ - V) - V; cantaba: $(\mathrm{O}-\mathrm{V})$ o V ; cantaría: $(\mathrm{O}-\mathrm{V})+\mathrm{V}$. Existe sólo una forma específica referida a un punto posterior al origen: habré cantado $(\mathrm{O}+\mathrm{V})-\mathrm{V}$. Algo similar ocurre con habría cantado: $((\mathrm{O}-\mathrm{V})+\mathrm{V})-\mathrm{V})$. He cantado responde a la fórmula $(\mathrm{O}$ o $\mathrm{V})-\mathrm{V}$ e indica la anterioridad con respecto a una referencia simultánea al origen. Es interesante la observación de Rojo que concluye la estructuración presentada con lo de que «todas

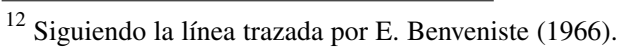


las formas son relativas en diferentes grados: con respecto a un punto cero (origen), a una referencia ordenada en relación al origen o bien a dos referencias, una de las cuales está situada con respecto al origen y la otra orientada a partir de la anterior.» (Rojo; 1974: 83). Es una clara réplica a la concepción de S. Gili Gaya (1965) que diferencia las formas absolutas (con las que medimos directamente el tiempo y atribuimos valor absoluto) de las formas relativas (que son indirectamente medidas porque necesitan ser fijadas por el contexto). Estamos de acuerdo con Rojo de que podemos marcar diferentes (tres) grados de relatividad pero nunca hablar de formas absolutas.

Al mismo tiempo queremos enfatizar la importancia de las expresiones adverbiales en el estudio de la temporalidad verbal ya que representan junto con el morfema verbal dos fuentes principales para las indicaciones temporales.

\section{Análisis textual del poema $E l$ viaje definitivo de Juan Ramón Jiménez}

A continuación seguirá el análisis textual de la temporalidad verbal en el poema $E l$ viaje definitivo del poeta español Juan Ramón Jiménez basándose en los criterios metodológicos establecidos más arriba. El poema pertenece a su época temprana, llamada también la etapa moguereña (1905-1912) ${ }^{13}$. Es un poema corto, de verso libre, bastante simple a primera vista, pero con una densa red de relaciones interesantes que quedan manifestadas a través del análisis detallado.

\section{EL VIAJE DEFINITIVO}

...Y yo me iré. Y se quedarán los pájaros

cantando;

y se quedará mi huerto, con su verde árbol, y con su pozo blanco.

Todas las tardes, el cielo será azul y plácido; y tocarán, como esta tarde están tocando, las campanas del campanario.

Se morirán aquellos que me amaron;

y el pueblo se hará nuevo cada año;

y en el rincón aquel de mi huerto florido y encalado, mi espíritu errará, nostáljico...

Y yo me iré; y estaré solo, sin hogar, sin árbol verde, sin pozo blanco, sin cielo azul y plácido...

y se quedarán los pájaros cantando.

\footnotetext{
${ }^{13}$ Es una etapa cuando Juan Ramón vive fuertes depresiones (por la muerte de su padre, por el precario estado de su familia), pero se recupera con ayuda de la naturaleza, es decir, reencuentra la alegría perdida. Al devolvérsele el ánimo para enfrentarse con la vida y la escritura, no le abandona más su obsesión por la muerte que se va a reflejar en la mayoría de su obra posterior. Inseguridad, nostalgia, soledad pero a la vez tranquilidad y evocación de su mundo infantil van a estar también presentes en El viaje definitivo. Además de esto la etapa moguereña representa un cambio de orientación tanto en la nivel de métrica como en el contenido y el estilo; es un periodo «transitorio» hasta el salto cualitativo que supondrá la escritura del Diario de un poeta reciencasado.
} 
Entremos en el campo de la cohesión semántico-temática resumiendo el contenido del poema: el hablante está en su huerto, su locus amoenus (hasta locus aeternus), contemplando el cielo, la naturaleza y escuchando las campanas que estarán tocando por el inicio de un funeral. Es la reflexión sobre lo transitorio de lo humano por una parte (se morirán todos que lo amaron y él se irá) y de lo permanente de la naturaleza por otra (todo se quedará igual, los pájaros seguirán cantando, el árbol será verde, el pozo seguirá siendo blanco y hasta el cielo será del mismo color azul y plácido). Pero la transitoriedad humana es, en cierto modo, superada ya que su espíritu permanecerá aquí, en el mismo jardín donde errará nostálgico.

Al emprender el camino de análisis pragmático primero debemos fijarnos en el título, uno de los marcos del poema cuya presencia o ausencia ya indica la actitud del poeta y las respectivas técnicas poéticas. Pero, sin embargo, antes de nada tiene una función fática, es decir que advierte del comienzo del mensaje y dispone los ánimos de los lectores orientando así el proceso de descodificación. El viaje definitivo por una parte remite al tema del texto que es la reflexión que el poeta hace sobre qué pasará cuando muera, cuando emprenda este viaje definitivo, pero por otra resalta el símbolo fundamental que se articula en el discurso: no se va a tratar de un viaje cualquiera, sino de un viaje definitivo, un viaje fatal que está al final del «camino machadiano». El acto comunicativo nos sumerge en lo imprescindible, definitivo, y no quiere dejar dudas, se hablará de un viaje trascendente, de la muerte.

Pero mucho más llamativo desde el punto de vista comunicativo es el inicio; aparte de los puntos suspensivos empieza con la conjunción $Y$ (... Y se quedarán los pájaros cantando); lo que produce un efecto interesante: el lector está situado en medio de un discurso ficticio con la impresión de que el enunciado continúa desde un inicio anterior. Tiene que recuperar lo ya dicho por lo que se le va diciendo y queda manifestado que la poesía se acaba más allá donde ya no estamos presentes como lectores. Tiene el efecto de la insinuación pero inversa ya que ocurre en el inicio del discurso. La conjunción $Y$ es aún más decisiva en lo que atañe a la estructura textual conclusiva y sintética de este poema dado que forma el polisíndeton que destaca por su insistencia. Está esparcida por todo el poema; aparece en 10 de los 15 versos dando así una sensación de movimiento indispensable, de la rueda o noria de la vida, de este circulus vitiosus que nos atañe a todos. Y en efecto podemos sentir que se trata de un enunciado de todos, todos somos los hablantes ficticios convirtiendo así el «yo» del poema en un yo multiplicado. ... y yo me iré podría ser pronunciado por cualquiera de nosotros sin que se pierda el valor ilocutivo del enunciado. En el poema hay una evidente ausencia de la apelación a un tú lo que hace del discurso una pura expresión del «yo» en cuanto tal. La primera persona aparece explícitamente sólo 3 veces (me iré, me iré, estaré) entre las 13 formas personales del verbo en total, pero sin embargo el destino definitivo del «yo» ficticio se refleja en las demás acciones y estados expresados por los verbos.

Entre los mecanismos de la cohesión superficial (aparte del polisíndeton ya mencionado) destaca el políptoton: (se quedarán los pájaros - se quedará mi huerto; y tocarán como esta tarde están tocando; las campanas - del campanario) y los paralelismos de la primera estrofa (con su verde árbol, con su pozo blanco) y cuarta estrofa (sin hogar, sin árbol verde, sin pozo blanco, sin cielo azul y plácido) que contribuyen, entre otras cosas, a la gradación del ritmo del poema.

La cohesión y la coherencia de las relaciones temporales están basadas en el verbo cuya consecuencia es la temporalidad dinámica del discurso. La perspectiva predominante 
de la temporalidad lingüística ${ }^{14}$ es la posterioridad, es decir la relación $(\mathrm{O}+\mathrm{V})$ que se manifiesta con el futuro simple. Es una temporalidad verbal del plano actual (o del discurso) cargada de matices significativos y valores modales que a menudo exceden la simple referencia a un momento posterior. La presencia de las formas del futuro simple está distribuida a través de todas las estrofas (3:2:3:3) dominando las demás formas verbales: entre las 13 formas personales del verbo hay 11 verbos en el futuro simple, uno en presente (el auxiliar de la perífrasis están tocando que la vamos a interpretar como presente actual) y un verbo en pretérito simple $(\mathrm{O}-\mathrm{V})$. En cuanto a los valores del futuro simple del poema se pueden divisar tanto los prospectivos como narrativos: se describe una situación desde el presente y se anticipa la acción que se sabe que sucederá por ser cíclica; por ser prevista y esperada.

El momento de la enunciación es esta tarde cuando están tocando las campanas $(\mathrm{O}$ o V). En aquellos que amaron tenemos dos señales de «no presencia»: aquellos y me amaron. Si la referencia fuera esta tarde, ya no me aman. Pero la referencia es en realidad algo borrosa, es más probable que sea cuando yo me mиеra; lo que añade al pretérito simple un valor de anticipación, es decir una sensación de que la acción de dejar de amar todavía está por ocurrir. Esta capacidad de expresar acciones que todavía no han ocurrido pero están a punto de realizarse no es nada ajena al pretérito simple ${ }^{15}$ y se debe al significado puntual que se refiere a la perfección del acto expresado. El enunciado «Ya llegué», expresado cuando, por ejemplo, un tren está a punto de llegar a la estación que es la destinación del hablante, es un ejemplo de la anticipación mental denotando la inminencia de la acción ya que no se ven ningunas razones que impidan su realización. Resumiendo: el pretérito simple en Se morirán aquellos que me amaron tiene el valor de anticipación; expresa una anterioridad de todo lo que pasará $((\mathrm{O}+\mathrm{V})-\mathrm{V})$, donde la perfección, el término de la acción de amar, predomina sobre el valor temporal del pretérito simple. En aquel momento, cuando «yo me vaya», ya serán aquellos, es decir no estarán (se morirán) y no me querrán; el pasado existirá y se manifestará en un futuro o, con las palabras del poeta: «por el futuro se llega al pasado» (J. R. Jiménez, 2001: 153).

Hay dos construcciones verbales con gerundio (vv. 1-2, 6). Se quedarán (los pájaros) cantando es una semiperífrasis puesto que el gerundio presenta todavía un fuerte valor adverbial o circunstancial. Con ella se enfatiza la continuidad de la acción de cantar tomándose como referencia un lugar más o menos determinado (en mi huerto) lo que se debe al significado locativo originario del verbo quedar(se). La perífrasis están tocando expresa aspecto durativo en el presente actual $(\mathrm{O}$ o V) que es el momento preciso de la enunciación.

Respecto a algunos adjetivos podemos divisar su carácter deíctico dado que los colores blanco, verde, azul y plácido aluden a la anterioridad, al alegre mundo infantil del «yo» hablante o, en este caso, también del autor implícito y empírico a la vez: el azul de su primera casa y del cielo andaluz, el blanco de la casa de la calle Nueva a la que se trasladó con cinco años: «La blanca maravilla de mi pueblo guardó mi infancia en una

\footnotetext{
${ }^{14}$ En este trabajo nos limitamos a estudiar la temporalidad lingüística de las formas verbales; en lo que se refiere a otras categorías verbales véase, entre otros, el interesante estudio de J. Calvo Pérez (1996) que es un intento de redefinir el paradigma del verbo español. Calvo Pérez aplica al futuro la fórmula ]A [, [+PTM] donde el único fondo no actualizado, o no necesariamente actualizado respecto al futuro es el aspecto (A), mientras que sí lo son persona (P), modo (M) y tiempo (T).

${ }^{15}$ Véase A. Bello (1847/1988) entre otros.
} 
casa vieja de grandes salones y verdes patios...» ${ }^{16} \mathrm{El}$ espacio que evocan los adjetivos es, claro está, Andalucía con pozo blanco, cielo azul y plácido; el huerto encalado es su «Jardín», un lugar idealizado convertido en el locus amoenus. En cuanto a la distribución de los adjetivos a través de las estrofas es llamativa cierta simetría donde los adjetivos de las primeras dos estrofas reaparecen en la última estrofa, hasta en el mismo orden (verde, blanco, azul, plácido). Con los cuatro adjetivos de la tercera estrofa guardan relación semántica: verdelflorido; blanco/encalado; azul/nuevo (en el sentido modernista); plácido/nostáljico; entretejiendo así la temporalidad futura y la realidad presente.

Desde el punto de vista de las unidades fónicas cabe mencionar la insistencia de las vibrantes que funciona como una onomatopeya indirecta del traqueteo de la noria de la vida. El sentimiento nostálgico y de la imposible salida del círculo temporal se transmite también con la rima asonante formada por las constantes $\boldsymbol{a}$ tónica y la o átona que resuenan a través de las cuatro estrofas del poema.

El discurso poético sobre el viaje definitivo empieza donde termina; es redondo como el tiempo juanramoniano ${ }^{17}$ cuyo movimiento circulatorio es su principal elemento constitutivo y coherente.

\section{Conclusión}

El enfoque pragmático del análisis del disurso poético no pretende buscar y encontrar la clave de toda la poesía de un poeta sino que aspira a aclarar algunos aspectos de la comunicación poética donde los elementos de sustancia que habitualmente carecen del valor significativo se cargan del valor y contribuyen al conjunto formal que es la comunicación lingüística de un poema.

La pragmática supone entonces un acercamiento dinámico al estudio del signo literario teniendo en cuenta las variantes de uso que están presentes en el proceso concreto de comunicación. Eso es posible si el análisis se centra en todos los momentos del proceso y no sólo en el texto como estructura fija. El discurso poético ofrece a su vez una forma de comunicación lingüística particular dado que está libre de las restricciones bajo las cuales se produce la comunicación cotidiana. Uno de los rasgos más representativos es la multiplicación de los niveles comunicativos, un punto de partida que debe ser considerado a la hora de aproximarse al discurso poético.

La utilización aparentemente diferente de los procedimientos gramaticales específicos de la poesía, entre ellos también los mecanismos de la temporalidad lingüística, no debe verse como una desviación de la gramaticalidad sino como ejemplo más puro de la comunicación lingüística (si repetimos las palabras de E. Alarcos Llorach) donde el autor es obligado a explotar y dominar hasta el máximo los recursos de una lengua y conseguir que todo sea coherente y pertinente. Esperamos que el presente análisis pragmático, centrado en mecanismos de la temporalidad lingüística, de sólo una pequeña parte del discurso poético juanramoniano, haya indicado cuánto todavía está por «conquistar» en la poesía, a pesar de que es bastante probable que nos quedemos con «la belleza y la fuerza» de la duda.

\footnotetext{
16 J. R. Jiménez (1999: 17).

17 »El tiempo es redondo como el mundo.«(J. R. Jiménez, 2001: 150).
} 


\section{BIBLIOGRAFÍA}

Alarcos Llorach, E. et al. (1973): El comentario de textos, Madrid: Editorial Castalia.

Adam, J. L. (1990): Éléments de linguistique textuelle. Liège: Mardaga.

Beaugrande, R. de, Dressler, U. (1997): Introducción a la lingüística del texto. Barcelona: Ariel Lingüística.

Bello, A. (1847/1988): Gramática de la lengua castellana destinada al uso de los americanos, I, II. Ramón Trujillo (ed.). Madrid: Arco Libros.

Benveniste, É. (1966): Problemas de lingüística general. México: Siglo XXI.

Bernárdez, E. (1995): Teoría y espistemología del texto. Madrid: Cátedra.

Bull, W. E. (1968): Time, Tense, and the Verb: A Study in Theoretical and Applied Linguistics, with Particular Attention to Spanish. Berkeley and Los Angeles: University of California Press.

Coseriu, E. (1996): El sistema verbal románico. México: Siglo XXI editores.

Criado de Val, M. (1992): La imagen del tiempo: Verbo y relatividad. Madrid: Istmo.

Ducrot, O. (1984): El decir y lo dicho. Buenos Aires: Hachette.

Fuentes Rodríguez, C. (2000): Lingüística pragmática y Análisis del discurso. Madrid: Arco/Libros.

Calvo Pérez, J. (1996): «Para un nuevo paradigma del verbo español». En: Verba, 23, 37-65.

Guillén, J. (1962/1992): Lenguaje y poesía. Madrid: Alianza Editorial.

Herrenstein Smith, B. (1993): Al margen del discurso. La relación de la literatura con el lenguaje. Madrid: Visor.

Jiménez, J. R. (1999): Antolojía poética. M. A. Vázquez Medel (ed.). Madrid: Editorial Biblioteca Nueva.

Jiménez, J. R. (1999): Antología poética. J. Blasco (ed.). Madrid: Cátedra.

Jiménez, J. R. (2001): Tiempo. Mercedes Juliá (ed.). Barcelona: Seix Barral.

Lamíquiz, V. (1994): El enunciado textual. Análisis lingüístico del discurso. Barcelona: Ariel Lingüística.

Levin, S. R. (1987): «Consideraciones sobre qué tipo de acto de habla es un poema». En: Pragmática de la comunicación literaria. Madrid: Arco/Libros, 59-82.

Luján Atienza, Á. L. (2000): Cómo se comenta un poema. Madrid: Editorial Síntesis.

Morris, C. (1985): Fundamentos de la teoría de los signos. Barcelona: Paidós.

Miklič, T. (1994): «Besedilni mehanizmi učasovljanja zunajjezikovnih situacij». En: Uporabno jezikoslovje 2 (2). Ljubljana, 80-99.

Reyes, G. (1990): La pragmática lingüística. El estudio del uso del lenguaje. Barcelona: Montesinos.

Reyes, G. (2002): Metapragmática. Lenguaje sobre lenguaje, ficciones, figuras. Valladolid: Secretariado de publicaciones e intercambio editorial, Universidad de Valladolid.

Rojo, G. (1974): «La temporalidad verbal en español». En: Verba, 1, 68-149.

Van Dijk, T. (1998): Texto y contexto. Madrid: Cátedra.

Weinrich, H. (1974): Estructura y función de los tiempos en el lenguaje. Madrid: Gredos. 


\section{PRAGMATIKA POETIČNEGA DISKURZA S POSEBNO POZORNOSTJO NA JEZIKOVNO-ČASOVNIH ODNOSIH}

Članek obravnava jezikovno-časovne odnose v poetičnem diskurzu kot komunikacijskem dogodku. Analiza poetičnega besedila El viaje definitivo Juana Ramóna Jiméneza temelji na izsledkih besediloslovnih in pragmatičnih študij, posebej na besedilnih kriterijih kohezije in koherence, ki predstavljata temeljna konstitutivna dejavnika besedila. Predpostavka, da je besedilo rezultat delovanja dinamičnih zakonitosti jezikovne strukture, usmeri žarišče proučevanja na moment besedilne produkcije in njegovo uporabo. Tukaj avtorica članka razločuje, najprej, med besedilom in diskurzom, kjer je diskurz širša dinamična komponenta, ki vključuje besedilo in njegov kontekst $v$ konkretni sporazumevalni situaciji; ter med naravnim in fiktivnim diskurzom, kjer je slednji mesto vzpostavitve pesniške komunikacije. Vsebina pesniškega besedila namreč ni ne resnična ne lažna, ampak izmišljena, iz česar sledi, da imajo pesniška govorna dejanja poseben status: so «parazitska», fiktivna; njihova ilokutivna moč se razlikuje od moči resničnih izjav naravnega diskurza. Pesniški diskurz torej ni prezentacija določenih vsebin, temveč je prezentacija diskurza o teh vsebinah oziroma njegova imaginacija, kar pogojuje mnogovrstnost in zapletenost sporazumevalnih odnosov, ki se v takem fiktivnem diskurzu vzpostavljajo. Tako se omogoča specifično okolje za raznolike jezikovne mehanizme, kjer so za avtorico članka še posebej pomembni mehanizmi učasovljanja. 